\section{Brazilian Journal \\ of Chemical \\ Engineering}

ISSN 0104-6632

Printed in Brazil www.scielo.br/bjce

Vol. 34, No. 03, pp. 727 - 738, July - September, 2017

$($ (c) $)$ EY

dx.doi.org/10.1590/0104-6632.20170343s20150729

\title{
A SIMULATION STUDY ABOUT THE IMPACT OF BIODIESEL USE ON THE ATMOSPHERE OF RIO DE JANEIRO CITY
}

\author{
R. C. G. Oliveira ${ }^{1}$, C. L. Cunha ${ }^{1}$, S. M. Corrêa ${ }^{2 *}$, A. R. Torres ${ }^{2}$ and E. R. A. Lima ${ }^{1}$ \\ ${ }^{1}$ Chemistry Institute, Rio de Janeiro State University, Rio de Janeiro, RJ, Brazil, 20550-013 \\ ${ }^{2}$ Faculty of Technology, Rio de Janeiro State University, Resende, RJ, Brazil, 27537-000 \\ * Corresponding Author: sergiomc@uerj.br
}

(Submitted: November 10, 2015; Revised: January 31, 2016; Accepted: April 7, 2016)

\begin{abstract}
This study evaluates the impact of biofuels on the air quality of the city of Rio de Janeiro using an air quality model based on the trajectory model OZIPR associated with the SAPRC chemical model. The results show that the increase in biodiesel use reduces ozone levels in the atmosphere by $10.2 \%$, using Biodiesel with Ethanol and Diesel mixture (BE-Diesel), in $5.28 \%$, using B20 mixture and only $0.33 \%$ using B10. An increase was observed in NOx emissions of 5.66 and $2.83 \%$ for BE-Diesel mixture and B20, respectively. The low ozone levels are attributed to its consumption by NO. The CO concentration reductions for BE-Diesel, B20 and B10 were 13.11, 6.56 and 4.12\%, respectively. The presence of oxygen atoms within the biodiesel chain leads to a better combustion process, reducing CO emissions.
\end{abstract}

Keywords: Modeling; Simulation; Biofuels; Air quality.

\section{INTRODUCTION}

The Metropolitan Area of Rio de Janeiro (MARJ) is one of the largest urban regions in the world. It covers a total area over 4,690 $\mathrm{km} 2$ and represents $11 \%$ of the whole Rio de Janeiro State. Additionally, the MARJ is one of the most industrialized areas in South America and has one of the largest vehicular fleets in the world, about 2 million vehicles. The total number of inhabitants is approximately 11 million and the high levels of pollution constitute a critical health problem in the region (INEA, 2011). Besides this, there are some characteristics which can significantly increase air quality problems: topography, the presence of a big bay (Guanabara Bay) and several beaches, high temperatures and intense solar radiation, in addition to high population density. Brazilian vehicles use a mixture of anhydrous ethanol added to gasoline since the 1980s (with 20 to $27 \% \mathrm{v} / \mathrm{v}$ ) called gasohol, hydrated ethanol, $7 \%$ of biodiesel in diesel, and compressed natural gas (CNG), resulting in a very complex fuel matrix used by the fleet.

The main goal of this study is to evaluate the impact of biofuels on the air quality of the city of Rio de Janeiro and to study scenarios for air quality, due to the increase of biodiesel amount added to diesel (BXX) and ethanol (BE-Diesel). This study was performed as a first step in creating a base case with data collected by an automatic monitoring station during three months of the summer season from 2011 to 2012. The base case and scenarios were developed using the trajectory model OZIPR coupled with the chemical mechanism SAPRC.

Volatile Organic Compounds (VOCs) speciation in the atmosphere has been done by several authors in order to obtain a better understanding of the emission sources in urban areas (Blake and Rowland, 1995; Derwent et al., 2000; Na and Kim, 2001; Hsieh and Tsai, 2003; Barletta et al., 2005; Guo et al., 2006; Qin et al., 2007; Langford

\footnotetext{
* To whom correspondence should be addressed
} 
et al., 2010). Studies of the VOCs present in the urban atmosphere of Brazilian cities are still scarce and are concentrated in the cities of São Paulo, Rio de Janeiro and Porto Alegre (Grosjean et al., 1998; Vasconcellos et al., 2005; Orlando et al., 2010; Corrêa et al., 2003, 2007, 2010; and Garcia et al., 2013).

In the last decades a considerable reduction in the vehicular emissions was observed due tothe use of new technologies, such as electronic injection, catalysts, and a better fuel quality, following PROCONVE stages (Brazilian Control Program for Air Pollution from Motor Vehicles) where each step or phase requires further reductions in emissions of vehicle pollutants.

Some papers presented previously by Orlando et al. (2010), Garcia et al. (2013), and Souza et al. (2012) used OZIPR to simulate the air quality of great cities, using manual adjustment of the model parameters. In this procedure, variables such as emission rates, deposition coefficients, and mixing height profile were adjusted by a shooting approach to fit the modeled data. This procedure demands time, since it did not apply an appropriate parameter estimation procedure and the solution of the problem sometimes was not the best as it could be by using automatic heuristic methods. This paper propose a new approach using particle swarm optimization (PSO) method in order to estimate parameters and find a minimum value for the proposed objective function, considering the base case of Rio de Janeiro city.

\section{METHODOLOGY}

\section{Site Description}

This work used data from SMAC (Environmental Agency of Rio de Janeiro city), collected by an automatic monitoring station located at the State University of Rio de Janeiro (UERJ), from November 2011 to March 2012, from the end of spring to the end ofthe summer season $\left(22^{\circ} 54^{\prime} 37^{\prime \prime} \mathrm{S}, 43^{\circ} 14^{\prime} 05^{\prime}\right.$ W). Data collected included average hourly values of carbon monoxide (CO), carbon dioxide (CO2), nitrogen oxides ( $\mathrm{NO}$ and $\mathrm{NO} 2)$, ozone (O3), sulfur dioxide (SO2), total hydrocarbons (THC), temperature $(\mathrm{T})$, pressure $(\mathrm{P})$, relative humidity $(\mathrm{RH})$, solar radiation (SR), wind speed (WS) and wind direction (WD).

A sampling campaign for VOCs was carried out beside the automatic monitoring station during January and February, 2012. Two one-hour samples were collected per day: $06: 30 \mathrm{~h}$ to $07: 30 \mathrm{~h}$ and $07: 30 \mathrm{~h}$ to $08: 30 \mathrm{~h}$, on the 3rd, 4th, 9th, 16th and 27th days of January 2012, and also February 2nd, 2012. All of these days were without rain, weekdays, and with low cloud cover.

\section{Model Development}

The model was built using the trajectory model OZIPR (Ozone Isopleth Package for Research) (Gery and Crouse, 1990; Tonnesen, 2000), which was developed under a contract with the U.S. Environmental Protection Agency (EPA), as a supporting tool for forecasting scenarios of urban pollution. It is a simple one-dimensional model, known as box or trajectory model, which requires data that include initial concentrations, emissions, and meteorological parameters, with temporal resolution without spatial descriptions of these parameters.It is a dynamic model with concentrated parameters, i.e., the results obtained vary with time but not in space.

This model can be understood as a column of air that covers the studied area up to the mixing layer of the atmosphere, like a box with mobile lid of the height of the mixing layer during the day. The whole box is considered to be homogeneous and moves along the trajectory of the wind, but without horizontal expansion. No topography details are considered in this box model. Emissions from the base of the column and also dry and wet deposition are computed, together with thermal and photochemical reactions (Orlando et al., 2010).

The inputs for the simulation are data from the studied area, including: speciation of the VOCs; initial concentrations of $\mathrm{NO}, \mathrm{NO} 2, \mathrm{CO}, \mathrm{T}, \mathrm{P}, \mathrm{RH}$, and mixing layer height; primary emissions of $\mathrm{CO}, \mathrm{NOx}$ and THC, location, and date (to calculate the solar irradiation), dry and wet deposition coefficients, and the chemical mechanism. The output data are the hourly average concentrations.

The SAPRC (Statewide Air Pollution Research Center) mechanism was initially developed by Carter (1990) and was posteriorly updated by Carter (1994, 1995, 1996), Carter and Atkinson (1996), Carter and Lurmann (1991), and Carter et al. (1997).Itdeals with thermal and photochemical homogeneous reactions, with approximately 140 reactions and 80 species. Species of low importance and with little information regarding the reaction rate and the stoichiometry are not treated explicitly. This can also be used to reduce computational time.

As it is unfeasible to represent the whole chemical mechanism involved, with all explicit species, a methodology that groups them into classes was used. However, some species that have well-established reaction rates and/or are of great importance to the atmospheric chemistry are treated explicitly. The grouping criteria include similarities in structure and reactivity (Carter, 1990). Basically, five groups of alkanes, two groups of alkenes, four groups of carbonyls, and two groups of aromatics are used.

\section{Emission data}

To obtain CO, NOx, and VOCs emission rates, an estimation was performed using the annual emission of CO published by INEA (2009). This report states that theMARJ has an urbanized area of $1,255 \mathrm{~km} 2$. To make hourly emission calculations, a year of 313 days (without Sundays and holidays) was considered. For each day, $18 \mathrm{~h}$ of effective vehicle circulation were taken into account, as presented in Equation 1. 


$$
321000 \frac{t C O}{\text { year }} \cdot 1000 \frac{\mathrm{kg}}{t} \cdot \frac{1}{1255 \mathrm{~km}^{2}} \cdot \frac{1 \text { year }}{313 \text { days }} \cdot \frac{1 \text { day }}{18 \mathrm{~h}}=45 \mathrm{~kg} \mathrm{~km}^{-2} \mathrm{~h}^{-1} \mathrm{CO}
$$

\section{Ambient Concentration}

The model input data were the initial concentrations of $\mathrm{CO}, \mathrm{NOx}$, and VOC speciation. Hourly data of $\mathrm{CO}$, NOx, and $\mathrm{O} 3$ concentrations were also needed to compare these data with the values obtained by simulation, in order to adjust the parameters.

Ozone was monitored using an Ecotech PTY Serinus 10, NOx was measured using an Ecotech Serinus 40, NMHC was measured using an Ecotech VOC100 model, $\mathrm{CO}$ was measured using an Ecotech Serinus 30 and PM10 and PM2.5 were measured using an Ecotech Spirant BAM.

The VOC sampling methodology was based on TO-15 methodology (U.S.EPA, 1999). It consisted of sampling with 6-L stainless steel canisters, followed by cryogenic pre-concentration of the sample and subsequent analysis by GC-MS using a Varian 450GC 220MS as detailed in Garcia et al. (2013).

For the analysis of formaldehyde and acetaldehyde, the TO-11A methodology (U.S.EPA, 1997) was used. It consists of sampling with $\mathrm{SiO} 2$ cartridges coated with C18 and impregnated with 2,4-dinitrophenylhydrazine (DNPH). During sampling, carbonyls are converted into their hydrazone form. The cartridges were used at a flow rate of $1.0 \mathrm{~L} \mathrm{~min}-1$ for a period of two hours. The formed hydrazoneswere eluted from cartridges with acetonitrile and analyzed by HPLC using a C18 column and UV detection at $360 \mathrm{~nm}$ (Perkin Elmer series 200), as detailed in Garcia et al. (2013).

\section{Parameters adjustment}

The first adjustment of the model parameters was done to build the basecase. This was performed in two ways: one manually and another automatic. The first step is to fit the $\mathrm{CO}$ modeled values with experimental values. This is done first because of its low reactivity and it is essentially a primary pollutant.

Depending on the discrepancy between the simulated and experimental values, some adjustments are necessary in the hourly $\mathrm{CO}$ emissions to fit these values. The same is done for NOx and for VOC, as described in detail in the following sections.

In order to use OZIPR one should provide basically three data sets with approximately 84 adjustable variables that would be: emission and deposition rates for $\mathrm{CO}, \mathrm{NOx}$ and VOCs, and the height profile of the mixing layer. Manual adjustments are time consuming and difficult to be correctly performed, due to nonlinearities of the phenomena involved. However, it is important to note that the manual adjustment has been used in all works done previously (Garcia et al., 2013; Souza et al., 2012; Corrêa,2003, 2007, 2010; Orlando, et al., 2010).
In this work, an automatic procedure was designed to make these adjustments in a shorter period of time. The objective function was defined from the least squares method weighted by the inverse of the variance following the maximum likelihood principle, according to Equation 2, where the variable $\mathrm{Y}$ corresponds to the pollutant concentration, namely: $\mathrm{CO}, \mathrm{NOx}, \mathrm{O} 3, \sigma 2$ is the variance of the experimental fluctuations of the dependent variable, Nexp is the number of experiments and Fobj the objective function.

$$
F_{o b j}=\sum_{i=1}^{N_{\text {exp }}} \frac{\left(Y_{i_{-} \bmod }(x)-Y_{i_{-} \exp }\right)}{\sigma_{i}^{2}}
$$

In order to automate the comparison between the concentrations calculated by the model (OZIPR) with those obtained experimentally, a programming effort was necessary to load the input parameters and run OZIPR for each iteration of the optimization method. It is worth noting that, for each evaluation of the objective functions, OZIPR needs to be run using the input file containing the parameters given by the optimization method at that step. Also, after running OZIPR in each step, it is necessary to get the results from output files of OZIPR and calculate theobjective function from the concentration profiles predicted.

The optimization algorithm used was the particle swarm optimization (PSO), which is a stochastic optimization algorithm first proposed by Kennedy and Eberhart (1995). The idea is to mimic the movement of gregarious animals in order to perform a method for finding the global minimum of the objective function automatically. This global minimum in the present study corresponds to the best set of fitted parameters.

\section{Scenario study for the city of Rio de Janeiro}

For creating scenarios, it is first necessary to know the impact of emissions of each pollutant studied here: $\mathrm{CO}$, NOx and HC. However, as this study did not conduct emission measurements, a study of the current literature was done. Table 1 presents emission rates for Rio de Janeiro fleet and these data were used to guide the scenarios presented here. There are several works in the literature in this area, but only some of them could help due to several factors such as: using an engine compatible with the actual Brazilian fleet in a dynamometer bench in compliance with Brazilian regulations (ABNT NBR 14489, 2000; ABNT NBR6601, 2005).

Currently in Brazil the average fleet of diesel vehicles uses B7 in its composition. However, as the studies in 
the literature compare their results against the emission of standard diesel (B0), this work had to use the same methodology. This work aims to generate scenarios of B10 for light vehicles (SUV), B20 for truck and BE-diesel (diesel with ethanol) for heavy vehicles.

The base case was validated against experimental data and possible variations in emissions were tested. The emissions data for light and heavy vehicles were taken from the work of Anderson (2012).For BE-diesel emissions the work of Shi et al. (2006) was used.

\section{Stratification of the fleet}

Emissions considered in this work are the sum from stationary and mobile sources during the three months of monitoring data. We considered the report by CETESB (São Paulo State Environmental Agency) regarding vehicle emissions in 2012 (Table 2). The vehicular emissions in São Paulo were used for being the most recent and also because the fleet of São Paulo and Rio de Janeiro are the same type.
According to Table 1, 98\% of CO, $66.5 \%$ of NOx and $67.3 \%$ of $\mathrm{HC}$ are emitted by mobile sources. Of this total, also according to Table $2,8.36 \%$ of $\mathrm{CO}, 81.54 \%$ of NOx and $12.04 \%$ of $\mathrm{HC}$ are related to heavy vehicles (buses + trucks). Light diesel vehicles are responsible for $0.40 \%$ of $\mathrm{CO}, 3.67 \%$ of NOx, and $0.57 \%$ of $\mathrm{HC}$.

In this study the emissions profile - that is an input for the model - was changed according to Table 3. For example, using B20 for heavy vehicles results in an emission reduction of about $4.10 \pm 6.4 \%$ for CO. So a maximum reduction of $10.5 \%$ and a maximum increase of $2.3 \%$ in the emissions of $\mathrm{CO}$ were stipulated. It was performed the same calculation for both $\mathrm{HC}$ and NOx for heavy vehicles and light vehicles.

\section{Incremental reactivity scale}

To evaluate the VOC incremental reactivity scale, an addition/reduction of $0.2 \%$ of the total VOC for each VOC of interest was performed to calculate ozone changes (Tonnesen, 2000).

Table1. Emission rates by source type in MARJ (INEA, 2009).

\begin{tabular}{cccc}
\hline \multirow{2}{*}{ Pollutant } & Fixed & Mobile & Total \\
\cline { 2 - 4 } & & kt year-1 & 18.4 \\
PM10 & 10.6 & 7.8 & 63.3 \\
SO2 & 55.8 & 7.5 & 90.5 \\
NOx & 30.3 & 60.2 & 321 \\
CO & 6.3 & 314.7 & 79.3 \\
\hline
\end{tabular}

Table2. Relative contribution of sources ofair pollution(CETESB, 2012).

\begin{tabular}{cccc}
\hline Vehicles & CO (\%) & HC (\%) & NOx (\%) \\
\hline light vehicles & 57.95 & 61.10 & 11.99 \\
light commercial (diesel) & 0.40 & 0.57 & 3.67 \\
trucks + buses & 8.36 & 12.04 & 81.54 \\
others & 6.80 & 7.14 & 1.39 \\
motorcycles & 26.49 & 19.15 & 1.41 \\
total & 100 & 100 & 100 \\
\hline
\end{tabular}

Table 3. Summary of emissions data from previous works in the literature.

\begin{tabular}{|c|c|c|c|c|c|c|}
\hline \multirow{2}{*}{ Source } & \multicolumn{3}{|c|}{ Emissions (\%) } & \multicolumn{2}{|c|}{ Blend $(\%)$} & \multirow[b]{2}{*}{ vehicle } \\
\hline & $\mathrm{CO}$ & NOx & $\mathrm{HC}$ & biodiesel & ethanol & \\
\hline U.S.EPA (2002) & -11.00 & 2.00 & -21.00 & 20 & - & heavy \\
\hline Shi et al. (2006) & 0.00 & 11.40 & -4.20 & 20 & 5 & heavy \\
\hline Yanowitz and McCormick (2009) & -10.10 & 2.00 & -21.10 & 20 & - & heavy \\
\hline Hoekman et al. (2009) & -18.70 & -0.60 & -21.00 & 20 & - & heavy \\
\hline Hoekman et al. (2009) & -10.40 & 10.80 & -17.40 & 20 & - & light \\
\hline Karavalakis et al. (2009) & 11.78 & 13.70 & 0.00 & 20 & - & light \\
\hline Anderson (2012) & -0.70 & 1.10 & -1.60 & 5 & - & light \\
\hline Anderson (2012) & 2.70 & 5.10 & 4.20 & 10 & - & light \\
\hline Anderson (2012) & -4.10 & 3.50 & -5.70 & 20 & - & heavy \\
\hline Kalam et al. ${ }^{a}(2011)$ & -21.00 & 2.00 & -17.00 & 5 & - & light \\
\hline Kalam et al. ${ }^{\mathrm{b}}(2011)$ & -7.30 & -1.00 & -23.00 & 5 & - & light \\
\hline
\end{tabular}

${ }^{a}$ source from Palm oil; ${ }^{b}$ source from coconut oil. 
The average concentration of total VOC measured during the spring of 2012 at UERJ was $1120 \mathrm{ppbC}$. Therefore, each VOC found in the atmosphere had its concentration increased by $2.24 \mathrm{ppbC}(0.2 \%$ of total VOC concentration), while the remaining VOCs were kept unchanged. After this procedure, the fractions were recalculated and loaded into the model. Subsequently, the positive incremental reactivity $(\mathrm{IR}+)$ was determined by Equation 3.

$$
I R+=\frac{\left[\mathrm{O}_{3}\right]^{\text {inc }}-\left[\mathrm{O}_{3}\right]^{\text {base }}}{+0.002 \cdot[\text { VOCs }]^{\text {base }}}
$$

Then, the concentration of each VOC was decreased by $2.24 \mathrm{ppbC}$. The change in ozone indicates the negative incremental reactivity (IR-).

$$
I R-=\frac{\left[\mathrm{O}_{3}\right]^{\text {inc }}-\left[\mathrm{O}_{3}\right]^{\text {base }}}{-0.002 \cdot[\text { VOCs }]^{\text {base }}}
$$

Although the equations presented for IR + and IR-are the same, the results for each IR are different, because atmospheric chemistry is highly non-linear. The addition/ removal of an individual VOC can lead to different values for ozone and other secondary pollutants.

It is important to point out that the individual change for each VOC results in a modification of the speciation of VOC. Therefore, for each new simulation it is necessary to correct the fraction values of the VOC group.

Finally, the arithmetical average between IR + and IRprovides the incremental reactivity (IR) for each VOC in MARJ found according to Equation 5.

$$
I R=\frac{(I R+)+(I R-)}{2}
$$

\section{RESULTS AND DISCUSSION}

\section{Base case adjustment}

The first compound to have its parameters adjusted was $\mathrm{CO}$ for being a primary pollutant with low reactivity. After performing the best possible fit (closest approach between the model curve and the experimental curve), changing only the hourly $\mathrm{CO}$ emission input, the next step is to fitthe mixing layer height values. It is worth remembering that this adjustment occurs around the average values obtained from the emission inventory of INEA. As the mixing layer height directly influences the concentration of pollutants, these values were also adjusted to obtain a better approximation. Figure 1 shows the simulated value results compared to the average (experimental) values provided by the automatic monitor between December 21, 2011 and March 21, 2012.

After adjusting the $\mathrm{CO}$ input, $\mathrm{NOx}$ adjustments were performed. The NOx/CO ratio and $\mathrm{VOC} / \mathrm{CO}$ ratio do not remain fixed throughout the day, owing to fleet stratification, which varies throughout the day. In this stage, an adjustment in the hourly emissions was performed to reproduce the real situation, always keeping the daily average constant. Figure 2 shows the simulated values compared with the average values measured for the period, after the adjustments mentioned.

Once the adjustments were made for $\mathrm{CO}$ and NOx, the base case was then very close to the final stage. The next step was to adjust the hourly VOC emissions. As the model does not provide data concerning hourly VOC

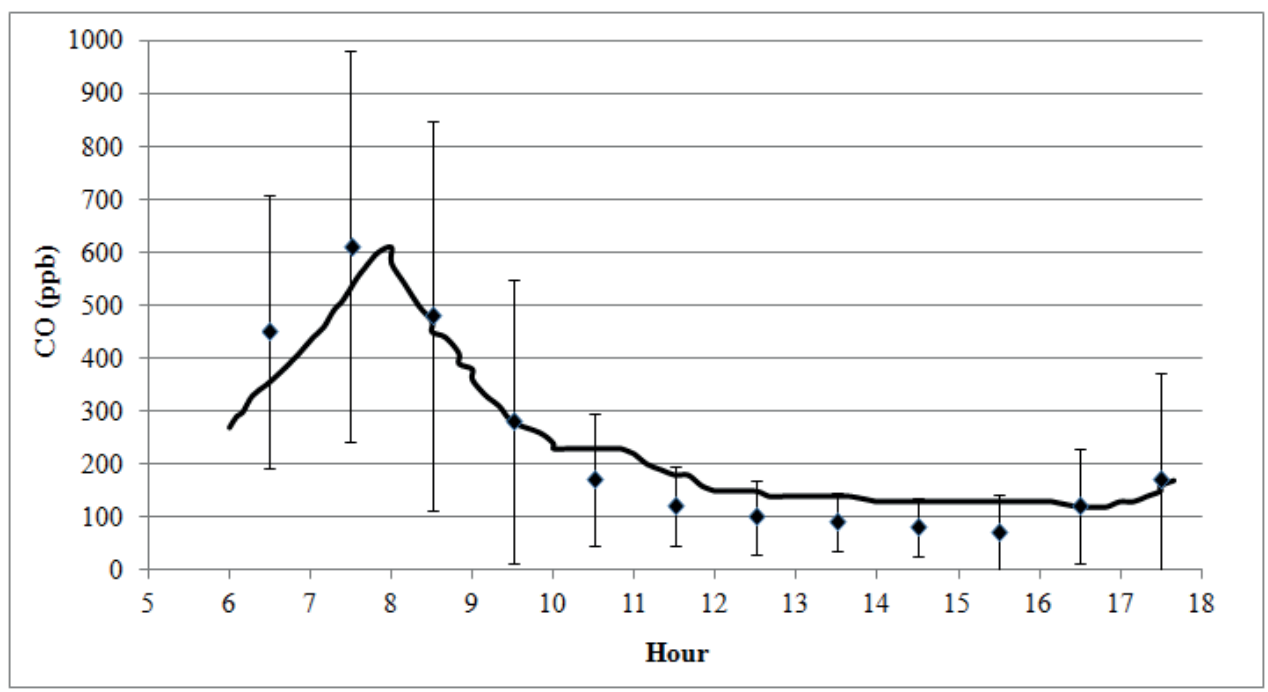

Figure 1. Hourly concentrations of CO (ppb) simulated (line) and experimental (symbols) for average days from December 21, 2011, to March 21, 2012, and the respective deviations, using manual adjustment. 
concentrations, this adjustment should be made using the ozone profile. A small adjustment in the ozone deposition rate was also carried out, following the ranges proposed by Finlayson-Pitts and Pitts (2000) (0.1 to $0.8 \mathrm{~cm} \mathrm{~s}-1)$. The adjusted ozone profile is presented in Figure 3.

The model was loaded with the average initial concentration data (between 6:30 and 9:30 am), hourly emissions of $\mathrm{CO}, \mathrm{NOx}$, and $\mathrm{VOC}$, and hourly data for $\mathrm{T}, \mathrm{RH}$, mixing layer height, and VOC speciation. These values are shown in Tables 4 and 5 .

To attempt fitting the model automatically, a previous emission behavior study throughout the day was conducted. The emissions of $\mathrm{CO}, \mathrm{NOx}$ and VOC tend to follow a profile with two characteristic peaks throughout the day, due to the increase of the vehicular fleet during the rush hours. The first peak occurs in the early hours of the morning at about $7 \mathrm{AM}$ and the second peak at about7 PM. As emissions occur during the whole day $(24 \mathrm{~h})$, the profile is not only limited to the morning hours, since emissions are accumulated throughout the day. In other words, there are residual emissions from the previous days (represented by $\mathrm{nf}$ ), as seen in Figures 4 and 5 . For this reason, this work uses a bimodal normal distribution function (two peaks). The purpose here is to reduce the number of input parameters, by working with the distribution parameters, instead of hourly emissions. To reach the purpose it is necessary that the distribution reproduce the experimental average emissions profile. Equation 6 shows the normal distribution function used where the variables $\mu, \sigma, \mathrm{Fe}, \mathrm{nf}$ corresponds to the parameters and $t$ is the time.

$$
F_{\text {dist }(t)}=\left(\left(\frac{1}{\sqrt{2 \pi \sigma^{2}}} e^{-\frac{1}{2}\left(\frac{t-\mu}{\sigma}\right)^{2}}\right) F_{e}\right)+n f
$$

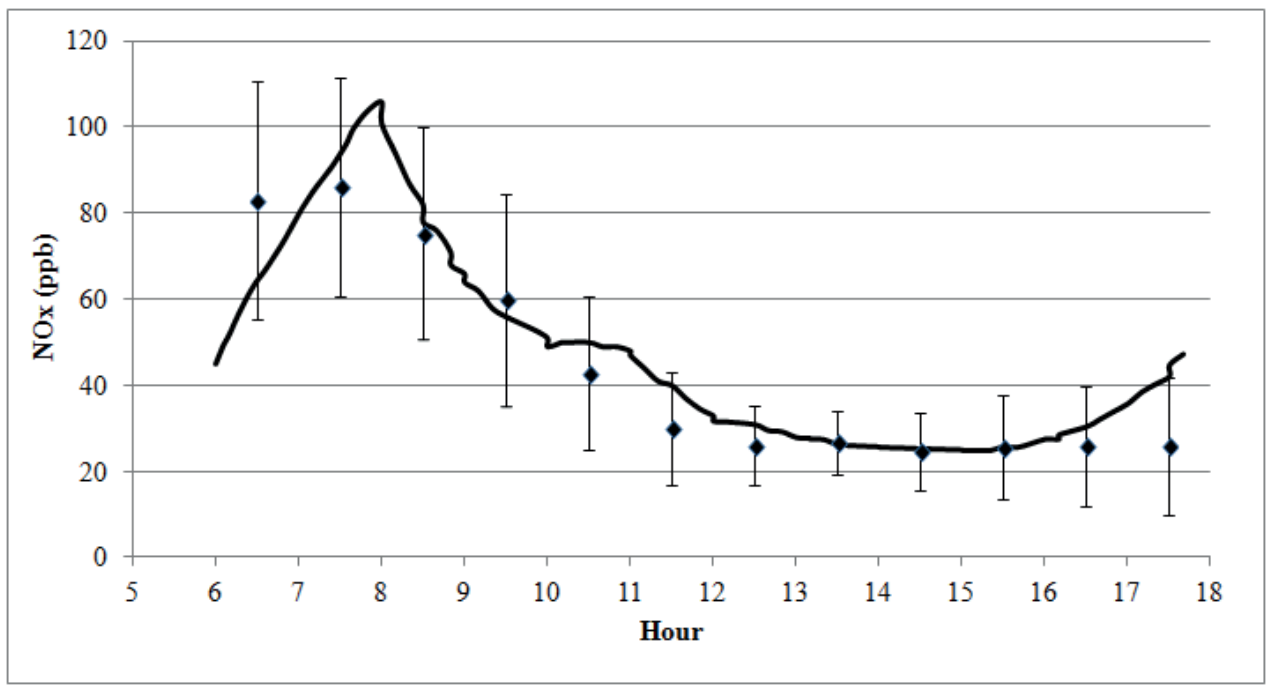

Figure 2. Hourly concentrations of NOx (ppb) simulated (line) and experimental (symbols) for average days from December 21, 2011, to March 21, 2012, and the respective deviation, using manual adjustment.

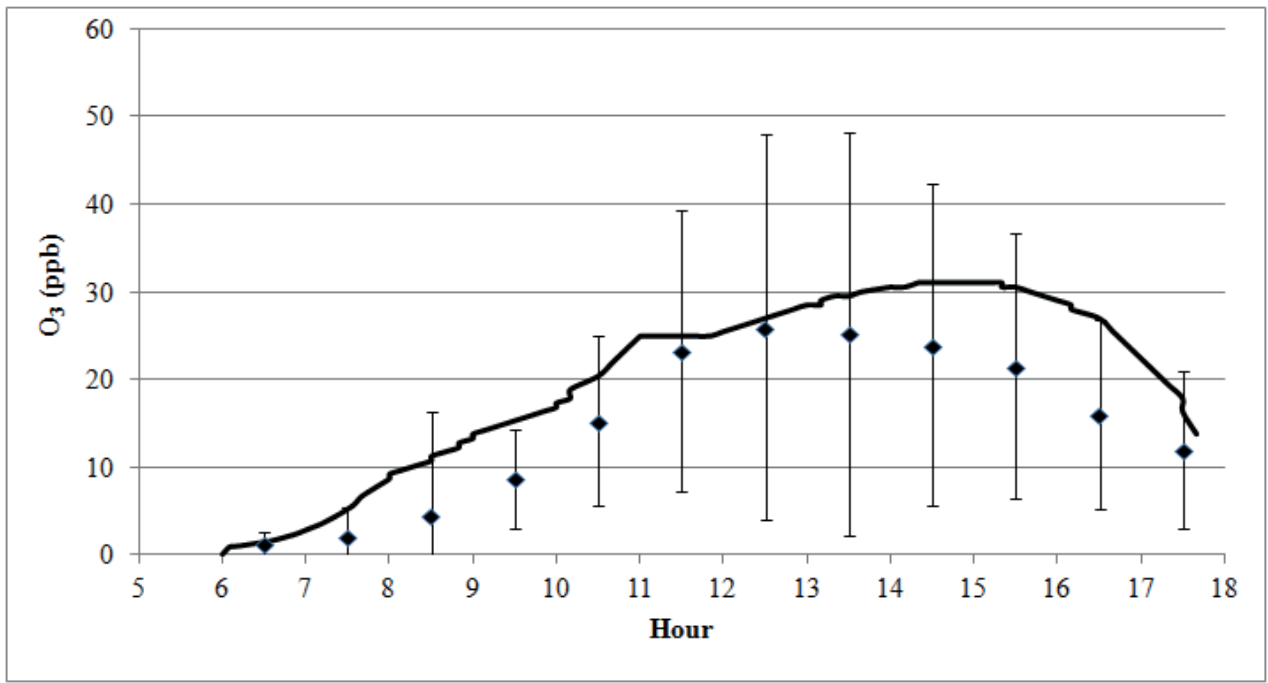

Figure 3. Hourly concentrations of Ozone (ppb) simulated (line) and experimental (symbols) for average days from December 21,2011 to March 21, 2012 and the respective deviation, using manual adjustment. 
Table 4. Initial concentrations of VOC, NOx, and CO for the base case.

\begin{tabular}{cc}
\hline $\begin{array}{c}\text { Compound } \\
\text { or group }\end{array}$ & $\begin{array}{c}\text { Initial } \\
\text { concentration }\end{array}$ \\
\hline CO & $0.49 \mathrm{ppm}$ \\
$\mathrm{NOx}$ & $0.09 \mathrm{ppm}$ \\
$\mathrm{VOC}$ & $1.12 \mathrm{ppmC}$ \\
\hline
\end{tabular}

Table 5. Values for temperature, relative humidity, mixing layer height for the base case.

\begin{tabular}{cccc}
\hline Hour & $\mathrm{T}\left({ }^{\circ} \mathrm{C}\right)$ & RH $(\%)$ & $\begin{array}{c}\text { Mixing } \\
\text { height }(\mathrm{m})\end{array}$ \\
\hline $06: 30$ & 25.37 & 77.76 & 200 \\
$07: 30$ & 26.72 & 72.10 & 250 \\
$08: 30$ & 28.16 & 65.74 & 300 \\
$09: 30$ & 29.33 & 60.24 & 650 \\
$10: 30$ & 30.44 & 56.00 & 1000 \\
$11: 30$ & 31.53 & 51.78 & 1450 \\
$12: 30$ & 32.13 & 50.12 & 1600 \\
$13: 30$ & 32.33 & 49.76 & 1700 \\
$14: 30$ & 32.28 & 50.05 & 1750 \\
$15: 30$ & 31.77 & 52.07 & 1050 \\
$16: 30$ & 31.07 & 53.86 & 800 \\
\end{tabular}

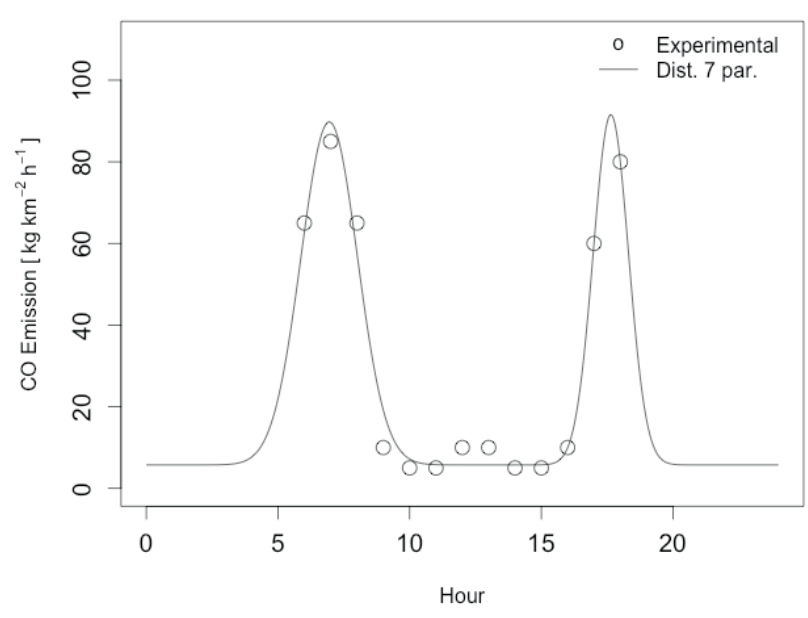

Figure 4. CO profilealong a typical day for Rio de Janeiro city.

The emissions data obtained from the manually validated model for each pollutant studied were used to "train" or adjust the normal distribution function in the automatic adjustment method, as seen in Figures 4 and 5.

As the mixing layer is also important for the adjustment procedure, it is necessary to load into the automatic model an average height profile of the mixing layer, as shown in Figure 6. A mixed layer follows a profile during the day close to a parabola. Equation 7 gives the curve used to represent the mixing layer.

$$
F(t)=a t^{2}+b t+c
$$

where the variables a, b, c, corresponds the parameters and $t$ is the time.

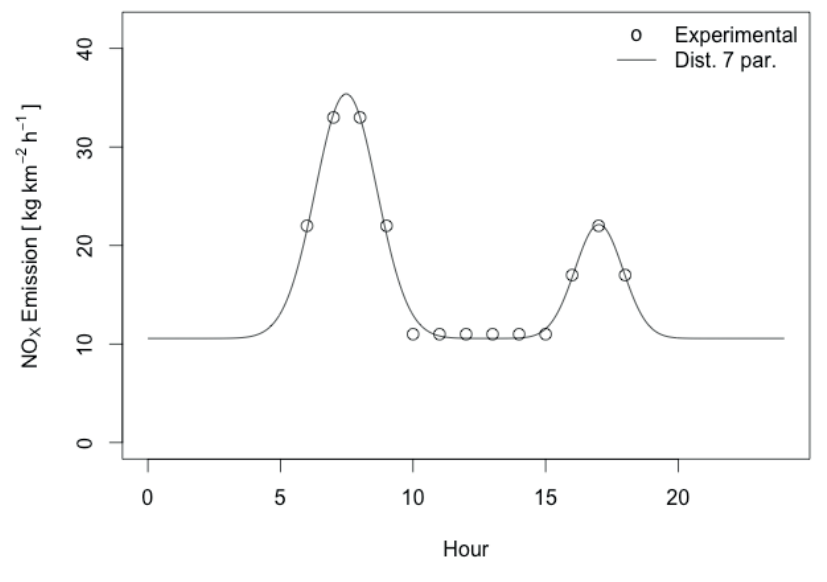

Figure 5. NOx profile along a typical day of Rio de Janeiro city.

Therefore, there are a total of 24 input parameters ( 7 for $\mathrm{CO}$ emission, 7 for NOx, 7 for VOC, and 3 for the mixing layer height). Deposition rates were changed, but since there is low sensitivity to changing these values, they were not included in the automatic adjustment.

The automatic adjustment response corresponds to a minimum value of the objective function. The total number of iterations is composed of the number of particles and the number of "flights" (steps) used. The number of particles was set to be 40 and the number of flights 200 , yielding a total of 8000 iterations. When the value of the objective function does not decrease further with increasing iterations, it means that the method found a local minimum that can be a global minimum or not. When that occurs, it indicates that a possible solution was obtained, as can be 


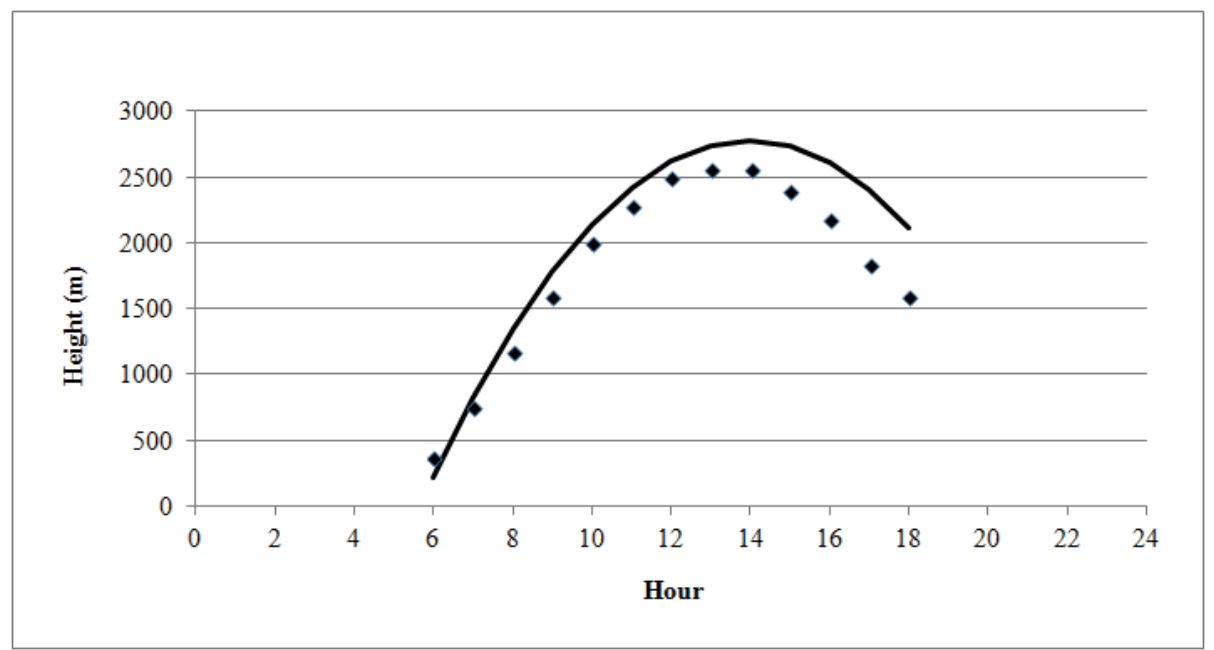

Figure 6. Mixing height profile simulated and experimental for the day 01/16/2012 for manual adjustment.

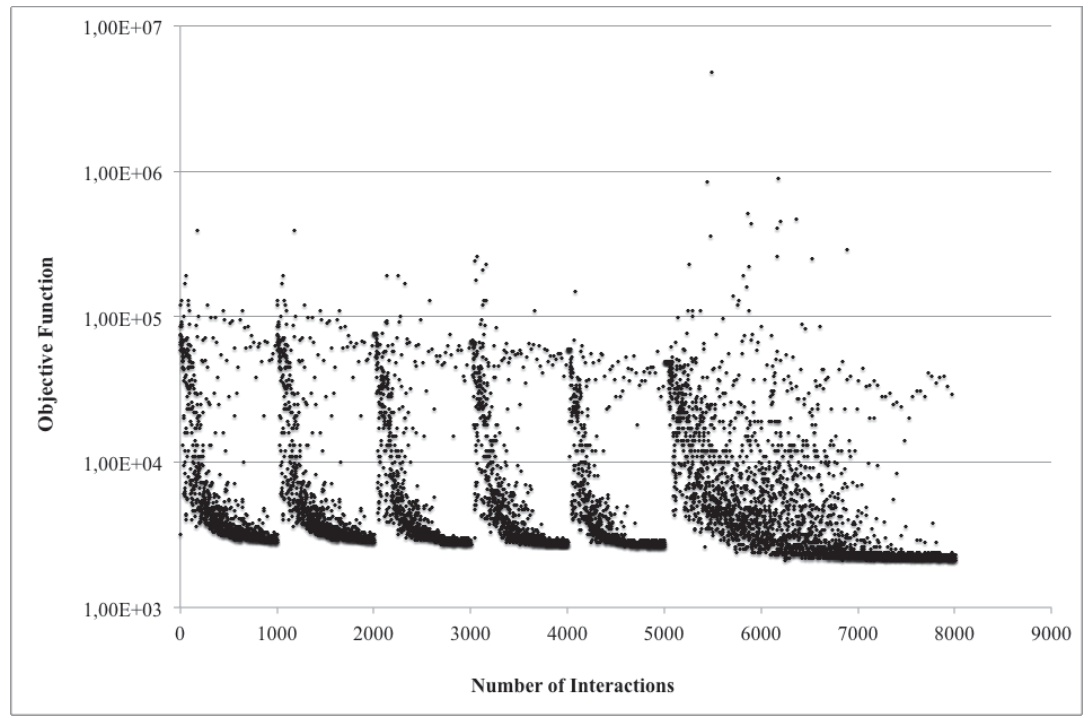

Figure7. Evolution of the objective function with iterations.

seen in Figure 7. In order to ensure that the global minimum has been found, the algorithm must be run several times.

It can be observed in Figure 7 that, in the first iterations, the stochastic optimization method PSO searches the entire region of study. Subsequently, the particles "communicate" with each other and the swarm is guided by the best answers obtained and finally reaches a minimum of the objective function. To start a new iteration, the best parameters that led to the lowest objective function are included in the next iteration of the algorithm, thus getting faster convergence to a minimum objective function.

Figure 8 presents the results obtained for the concentration of $\mathrm{CO}$ using the automatic procedure. The adjustment performed here has some deviations from the experimental values, even considering the errors bars. The manual adjustments presented in Figure 1 showed a better adjustment. However, considering the time-consuming procedure for the manual adjustment, the fast automatic adjustment can be considered acceptable.

For the concentration of O3 (Figure 9), the profile automatically adjusted during the day did not result in a very good answer. The model overestimates the concentration of $\mathrm{O} 3$ at the end of the day. As a secondary pollutant, O3 is formed by photochemical reactions involving NOx and VOC.

The attempt of using an automatic procedure for setting the parameters proved to be useful as it serves as a method for an initial adjustment. The automatic adjustment method becomes an excellent starting point. From its result, it is straightforward to do the fine adjustment manually, by using heuristic rules that are not so easy to automate, in order to find the best answer. Therefore, the use of this automatic first step for adjusting the parameters means a great decrease in the time necessary tofind the best answer, 


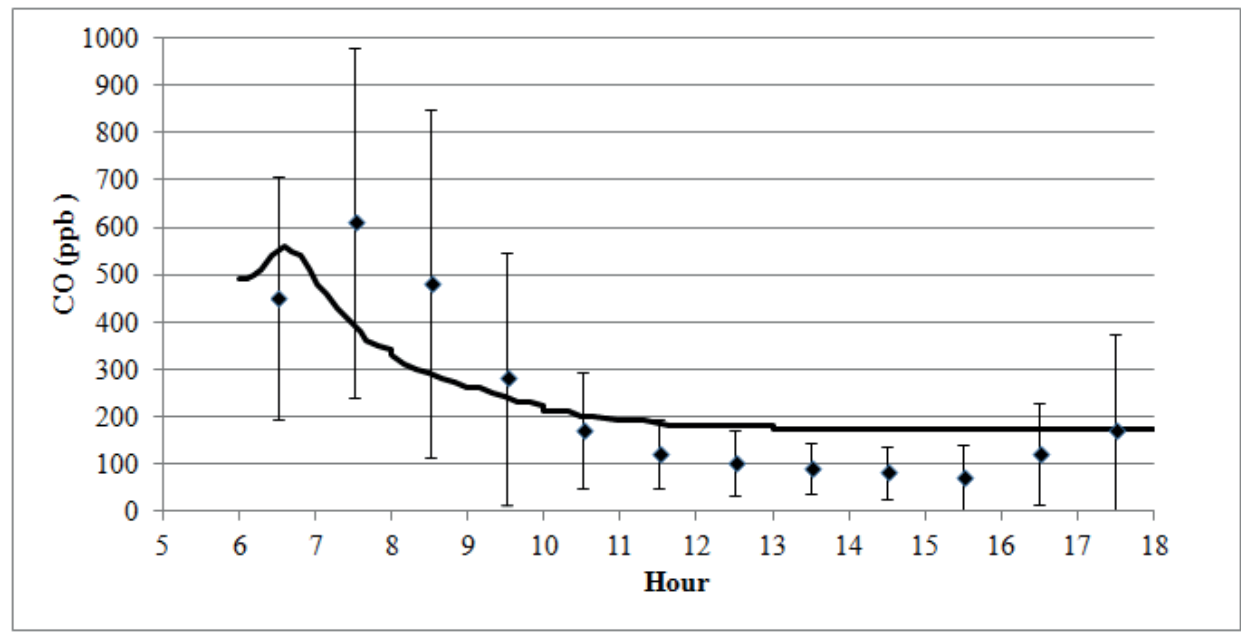

Figure 8. Hourly concentrations of $\mathrm{CO}(\mathrm{ppb})$ simulated using the automatic adjustment and experimental data for average days between December 21, 2011, to March 21, 2012, and the respective deviation bars for each time of day.

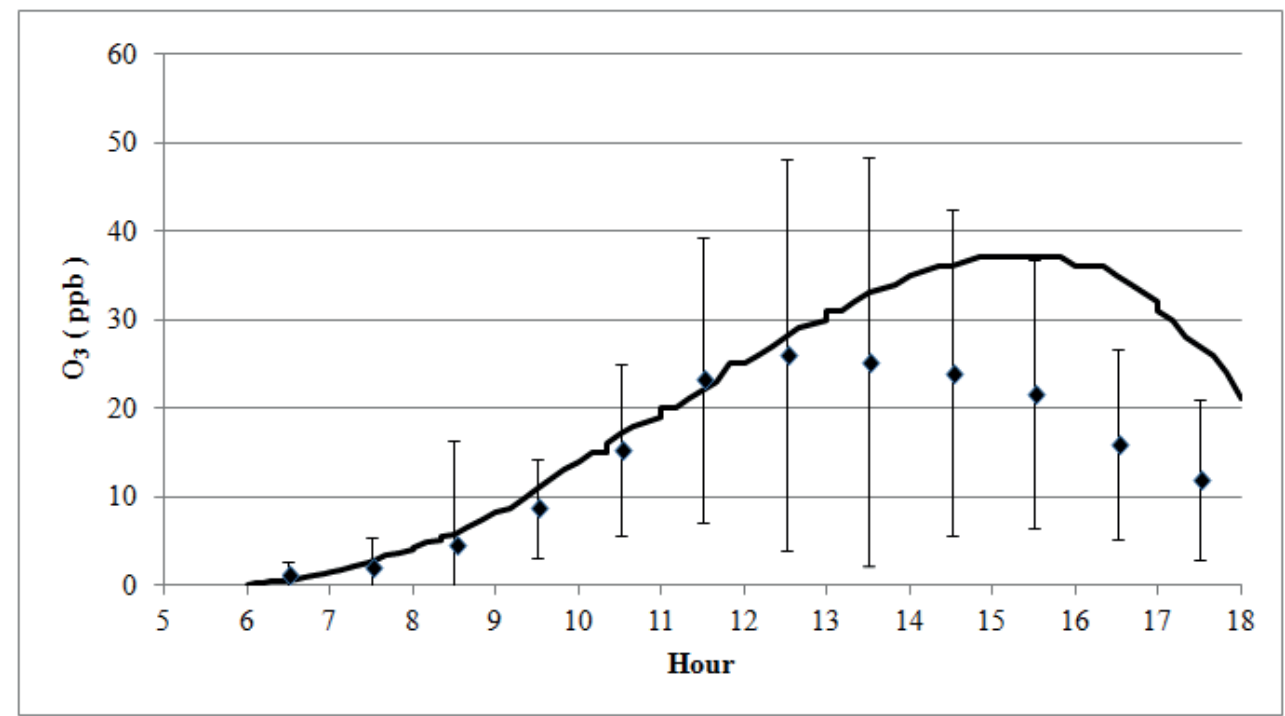

Figure 9. Hourly concentrations of O3 (ppb) simulated and experimental for average days between December 21, 2011, to March 21, 2012, and their deviation bars for each time of day for the automatic adjustment.

since the purely manual adjustment is very time consuming.

To improve the results obtained from the automatic procedure it is necessary to better understand the atmospheric phenomena involved for each pollutant previously studied. This wayit is possible to change the objective function to prioritize more relevant points at the expense of others not so important (by using weights). Thus, it would be possible to propose an objective function that gives priority to the most important measurements, making the search more efficient. This is a good challenge for future works in the area.

To quantify the VOCs incremental reactivity, a study was performed with the 20 major VOC ozone precursors in the city of Rio de Janeiro during the summer base case. We note that the alkenes have more influence on the results, as these molecules are very reactive, as detailed in Figure 10.
Taking as example the case of formaldehyde, Figure 10 indicates that increasing $1.0 \mu \mathrm{g} \cdot \mathrm{m}-3$ the concentration of formaldehyde, while keeping unchanged all the other VOC leads to an increase in ozone of $0.5 \mu \mathrm{g} \cdot \mathrm{m}-3$. Thus, the incremental reactivity scale may be a useful tool for decision makers in order to minimize the emission of more reactive VOC. As possible applications of this study we can mention givingsubsidiesto petrochemical companies in the formulationof fuels andfor environmental institutes on the regulation to reduce emissions of certain molecules by respective sources.

Besides the results for the scenarios studied, the model also allows performing multiple simulations of maximum ozone produced from different concentrations of VOCs and NOx, providing an isopleths diagram (lines of equal concentrations). Figure 11 presents ozone isopleths as 


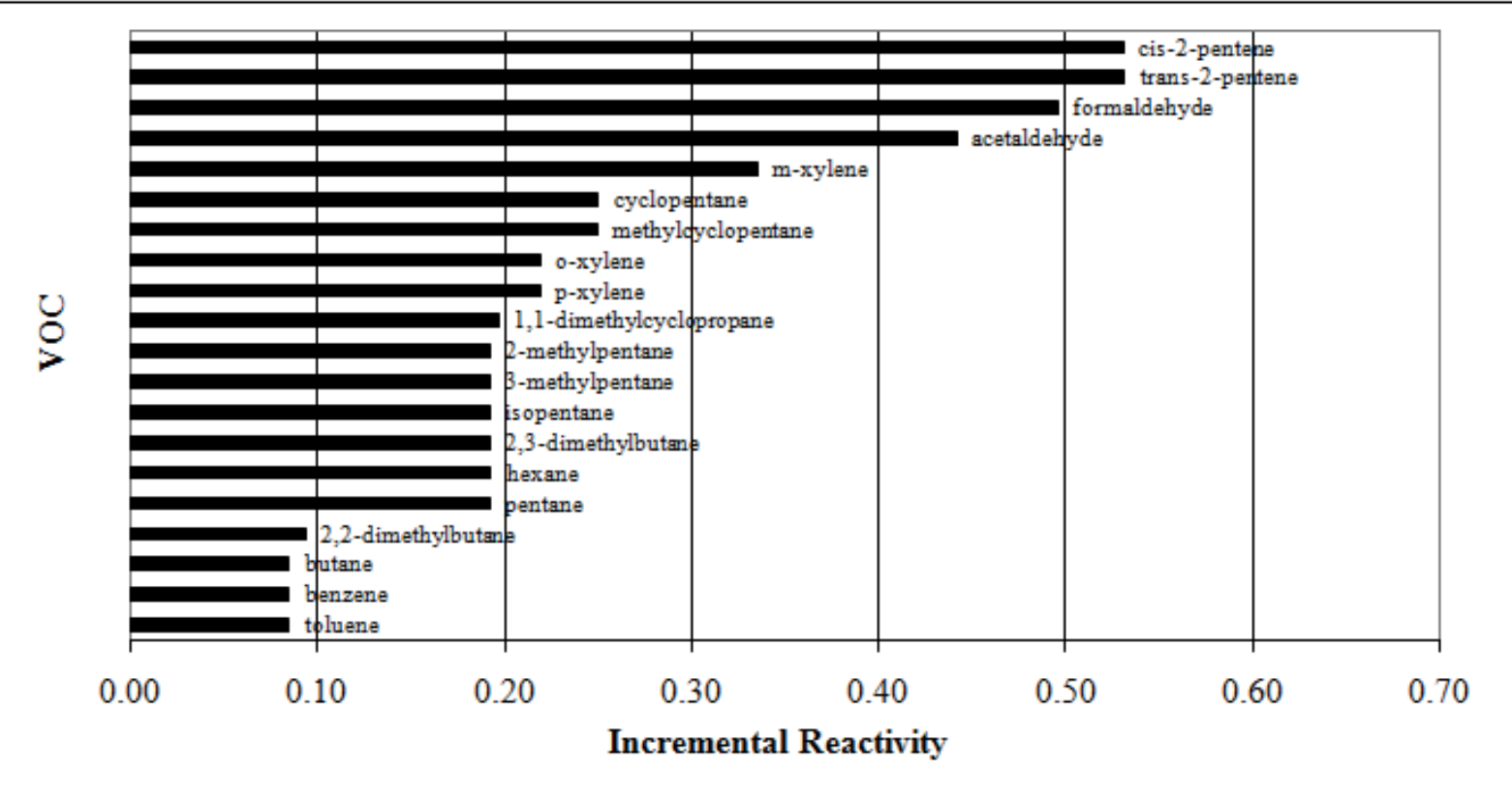

Figure 10. Incremental Reactivity scale for the main VOCs at MARJ.

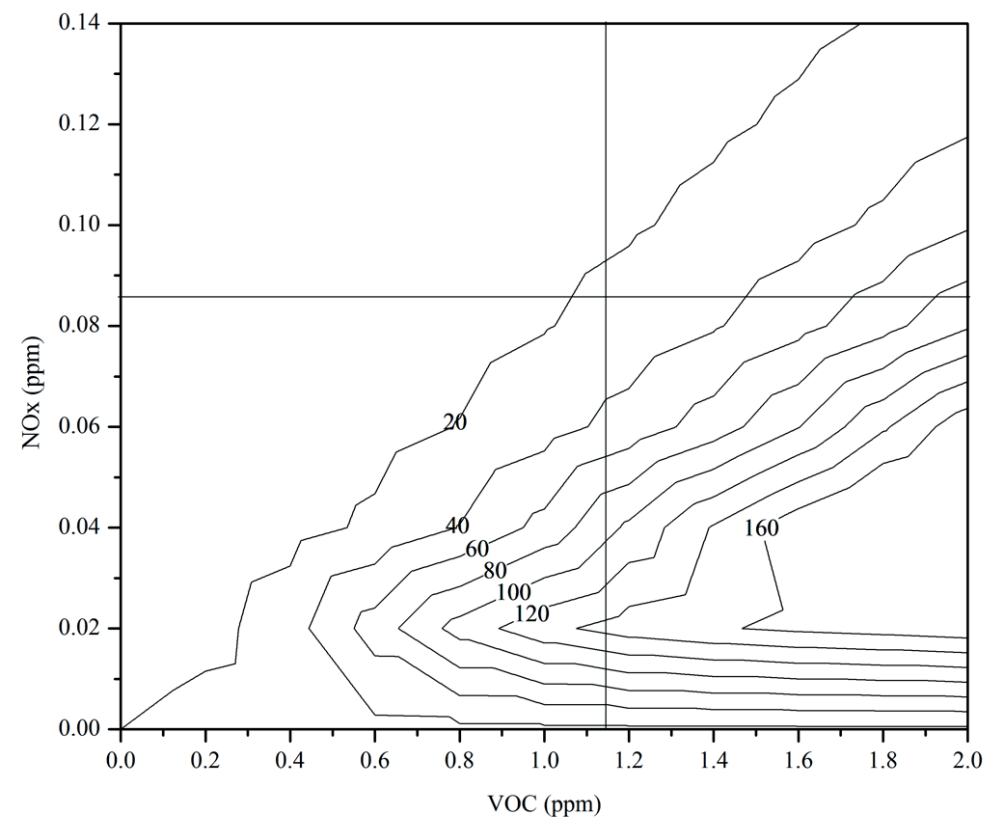

Figure 11. Ozone isopleths (ppb) for various concentrations of VOC and NOx, for the ase case.

a function of NOx and VOCs. The region where the two straight lines intersect corresponds to the base case for the city of Rio de Janeiro. According to Figure 11, one can see that there is a tendency to decrease the concentration of $\mathrm{O} 3$ as the concentration of $\mathrm{NOx}$ increases. On the other hand, the concentration of $\mathrm{O} 3$ increases as the VOCs concentrations increase.

For scenarios with the B10, B20 and BE-diesel there are a decrease in ozone concentration. The greater concentration of oxygenates in biodiesel causes a higher combustion temperature and consequently an increase in NOx emissions to the atmosphere. These results are presented in Table 6.

It can be observed, according to Table 6, that the increase of biodiesel in diesel causes a decrease in the concentration of $\mathrm{CO}$. This actually happens due to a greater availability of oxygen in the combustion gases in the engine, thus favoring the complete burning of the fuel. 
Table 6. Values for pollutants with additional use of biodiesel and BE-Diesel.

\begin{tabular}{|c|c|c|c|c|c|}
\hline \multirow{2}{*}{ Pollutants } & Base case & $\mathrm{B} 10$ & $\mathrm{~B} 20$ & BE - Diesel & \multirow{2}{*}{ Hour } \\
\hline & \multicolumn{4}{|c|}{$\mathrm{ppb}$} & \\
\hline $\mathrm{CO} \max$ & 610 & 580 & 570 & 530 & $8: 00$ \\
\hline NOx max & 106 & 106 & 109 & 112 & 8:00 \\
\hline O3 max & 30.3 & 30.2 & 28.7 & 27.2 & $14: 00$ \\
\hline
\end{tabular}

BE-Diesel showed up as the best option among mixtures of fuels covered in this study. Possibly, this is due to the inclusion of ethanol as an additive, having improved fuel combustion in the engine. However, it is noteworthy that there is a small increase in the concentration of NOx in the atmosphere, which is harmful to human beings.

Changesin the concentration values of the pollutants listed in Table 6are small because much of the emissions are due to fixed sources or mobile sources not included in the study, leaving only a small portion for mobile sources covering heavy or light vehicles (trucks) that use diesel as fuel.

A study where the concentration of heavy vehicles is higher, as in the case of highways, can lead to results with greater differences in the peak values of the pollutants.

\section{CONCLUSIONS}

This work presents a contribution o the understanding of legislated concentrations of pollutants in the city of Rio de Janeiro, as well as the contribution of these compounds to the tropospheric $\mathrm{O} 3$ concentration. The base case was developed and reproduced the experimental data for "manual" parameter setting, based on heuristic rules.

An automatic procedure for parameter adjustment has been proposed as an attempt to represent the average emission profile for each pollutant in the city of Rio de Janeiro, in order to express this profile through a wellknown mathematical function. This study demonstrated thatthe automatic adjustment could substantially decrease the adjustment effort, but did not lead to better answers in this situation. Thus, it can be used as an initial step before the "fine" manual parameters adjustment.

The scenarios studied here tested the impact of increasing the fraction of biodiesel or ethanol indiesel. The results obtained for $\mathrm{CO}$ and $\mathrm{O} 3$ showed a small decrease in the concentration of pollutants in the city of Rio de Janeiro in this situation. Nevertheless, the presence of oxygen in biodiesel and ethanol causes the increase in the emission and concentration of NOx, and leads to the increased consumption of $\mathrm{O} 3$ in the troposphere. Moreover, there is a better burning of the fuel, generating a lower concentration of $\mathrm{CO}$ in the atmosphere. However, there was an increasein the concentration of NOx in these scenarios.

It could also be observed in the study of isopleth curves that the urban atmosphere of the city of Rio de Janeiro is controlled by NOx.
The results of this study confirm the environmental issues related to economic development, especially in large urban centers. Air pollution results from the lack of collective thinking in regarding to air quality. The increase in the vehicular fleet in metropolitan regions justifies more academic research in this field. Thus, knowledge about the contribution of emissions generated by the operation of these vehicles and the search for cleaner technologies should be deeply encouraged. Furthermore, strict regulations and oversight by the government is necessary to assure the specifications will be met.

\section{ACKNOWLEDGMENTS}

The authors are thankful for data supported by CETESB, INEA, SMAC and for the financial support by CAPES, CNPq and FAPERJ.

\section{REFERENCES}

ABNT NBR 6601. Determination of hydrocarbon, carbon monoxide, nitrogen oxide, carbon dioxide and particulate material on exhaust gas. Rio de Janeiro, Brazil (2005).

ABNT NBR 14489. Diesel engine - Analysis and evaluation of gases and particulate matter emitted by the diesel engine - 13 mode cycle. Rio de Janeiro, Brazil (2000).

Anderson, L.G., Effects of biodiesel fuels use on vehicle emissions. Journal of Sustainable Energy Environment, 3, 35 (2012).

Barletta, B., Meinardi, S., Rowland, F.S., Chan, C-Yu, Wang, X., Zou, S., Chan, L.Y., Blake, D.R., Volatile organic compounds in 43 Chinese cities.Atmospheric Environment, 39, 5979 (2005).

Blake, D.R., Rowland, F.S., Urban leakage of liquefied petroleum gas and its impact on Mexico City air quality.Science,269, 953 (1995).

Carter, W.P.L., A detailed mechanism for the gas-phases atmospheric reactions of organic compounds. Atmospheric Environment, 24, 481 (1990).

Carter, W.P.L., Development of ozone reactivity scales for volatile organic compounds. Journal of the Air \&Waste Management Association, 44, 881 (1994).

Carter, W.P.L., Computer modeling of environmental chamber studies of maximum incremental reactivities of volatile organic compounds. Atmospheric Environment, 29, 2513 (1995).

Carter, W.P.L., Condensed atmospheric photooxidation mechanisms for isoprene, Atmospheric Environment, 30, 4275 (1996). 
Carter, W.P.L., Atkinson, R., Development and evaluation of a detailed mechanismfor the atmospheric reactions of isoprene and NOx. International Journal of Chemical Kinetics, 28, 497 (1996).

Carter, W.P.L., Luo, D., Malkina, I.L., Environmental chamber studies for development of an update photochemical mechanism for VOC reactivity assessment. Final Report to the California Air Resources Board, Contract 92- 345 (1997).

Carter, W.P.L.,Lurmann, F.W., Evaluation of a detailed gasphase atmospheric reaction mechanism using environmental chamber data. Atmospheric Environment, 25, 2771 (1991).

CETESB. <http://www.cetesb.sp.gov.br/ar/qualidade-do-ar/31publicacoes-e-relatorios $>$. Acessed in February 2, 2013.

CETESB. Qualidade do ar: poluentes. $<$ http://www.cetesb. sp.gov.br/ar/ /emissao-veicular/48-relatorios-e-publicacoes>. Accessed in January 1, 2013.

CETESB. Air quality report for the São Paulo state, ISSN01034103 (2012).

CETESB.Air quality report for the São Paulo state,ISSN0103-4103 (2011).

Corrêa, S.M., Martins, E.M., Arbilla, G., Formaldehyde and acetaldehyde in a high traffic street of Rio de Janeiro. Atmospheric Environment, 37, 23 (2003).

Corrêa, S.M., Arbilla, G., A two-year of aromatic hydrocarbons monitoring at the downtown area of the city of Rio de Janeiro. Journal of the Brazilian Chemical Society, 18, 539 (2007).

Corrêa, S.M., Arbilla, G., Martins, E.M., Quitério, S.L., Guimarães, C.S., Gatti, L.V., Five-years of formaldehyde and acetaldehyde monitoring in the Rio de Janeiro downtown area - Brazil. Atmospheric Environment, 44, 2302 (2010).

Derwent, R.G., Davies, T.J., Delaney, M., Dollard, G.J., Field, R.A., Dumitrean, P., Nason, P.D., Jones, B.M.R., Pepler, S.A., Analysis and interpretation of the continuous hourly monitoring data for $26 \mathrm{C} 2-\mathrm{C} 8$ hydrocarbons at 12 United Kingdom sites during 1996. Atmospheric Environment, 34, 297 (2000).

Finlayson-Pitts, B.J.,Pitts, J.N., Chemistry of the upper and lower atmosphere.San Diego: Academic Press (2000).

Garcia, L.F.A., Corrêa, S.M., Penteado, R., Daemme, L.C., Gatti, L.V., Alvim, D.S., Measurements of emissions from motorcycles and modeling its impact on air quality. Journal of the Brazilian Chemical Society, 24, 375 (2013).

Gery, M.W., Crouse, R.R., User's guide for executing OZIPR. U.S. Environmental Protection Agency (1990).

Grosjean, E., Rasmussen, R.A., Grosjean, D., Ambient levels of gas phase pollutants in Porto Alegre, Brazil. Atmospheric Environment, 32, 3371 (1998).

Guo, H., Wang, T., Blake, D. R., Simpson, I. J., Kwok, Y. H., Li, Y. S., Regional and local contributions to ambient nonmethane volatile organic compounds at a polluted rural/ coastal site in Pearl River Delta, China. Atmospheric Environment, 40, 2345-2359 (2006).

Hoekman, S.K., Gertler, A., Broch, A., Robbins, C., Investigation of biodistillates as potential blendstocks for transportation fuels CRC project No. AVFL-17, Coordinating Research Council, Inc. (2009).
Hsieh, C.C., Tsai, J.H., VOC concentration characteristics in southern Taiwan. Chemosphere, 50, 545 (2003).

INEA, 2009.Annual air quality report for the Rio de Janeiro state. http://www.inea.rj.gov.br/downloads/relatorios/qualidade ar_2009.pdf. Accessed in January 4, 2013.

INEA, 2011. Annual air quality report for the Rio de Janeiro state. http://www.inea.antigo.rj.gov.br/fma/qualidade-ar.asp. Accessed in July 13, 2015.

Kalam, M.A., Masjuki, H.H., Jayed, M.H., Liaquat, A.M., Emission and performance characteristics of an indirect ignition diesel engine fuelled with waste cooking oil. Energy, 36, 397 (2011).

Karavalakis, G., Alvanou, F., Stornas, S., Bakeas, E., Regulated and unregulated emissions of a light duty vehicle operated on diesel/palm-based methyl ester blends over NEDC and a nonlegislated driving cycle. Fuel, 88, 1078 (2009).

Kennedy, J., Eberhart, R., Particle swarm optimization. In: Proceedings of the IEEE international conference on neural networks, Perth, Australia, v. 4, 1942 (1995).

Langford, B., Nemitz, E., House, E., Phillips, G.J., Famulari, D., Davison, B., Hopkins, J.R., Lewis, A.C., Hewitt, C.N., Fluxes and concentrations of volatile organic compounds above central London, UK. Atmospheric Chemistry and Physics, 10,627 (2010).

Na, K.,Kim, Y.P., Seasonal characteristics of ambient volatile organic compounds in Seoul. Atmospheric Environment, 35, 2603 (2001).

Orlando, J.P., Alvim, D.S., Yamazaki, A., Corrêa, S.M., Gatti, L.V., Ozone precursors for the São Paulo metropolitan area. Science of the Total Environment, 408, 1612 (2010).

Qin, Y., Walk, T., Gary, R., Yao, X., Elles, S.,C2-C10 nonmethane hydrocarbons measured in Dallas, USA-Seasonal trends and diurnal characteristics. Atmospheric Environment, 41, 6018 (2007)

Shi, X., Xiaobing, P., Yujing, M., Hong, H., Shijin, S., Jianxin, W., Hu, C., Rulong, L., Emission reduction potential of using ethanol-biodiesel-diesel fuel blend on a heavy-duty diesel engine. Atmospheric Environment, 40, 2567 (2006).

Souza, C.V., Corrêa, S.M., Sodré, E.D., Teixeira, J.R., Volatile organic compound emissions from a landfill, plume dispersion and the tropospheric ozone modeling. Journal of the Brazilian Chemical Society, 23, 496 (2012)

Tonnesen, G.S., User's guide for executing OZIPR version 2.0. North Caroline: U.S.EPA (2000).

U.S. EPA. Compendium method TO-11. Determination of formaldehyde in ambient air using adsorbent cartridge followed by high performance liquid chromatograph. EPA/625/R-96/010b (1997).

U.S.EPA. Compendium method TO-15. Determination of volatile organic compounds (VOC) in air collected in speciallyprepared canisters and analyzed by gas chromatography/mass spectrometry. EPA/625/R-96/010b (1999).

Vasconcellos, P.C., Carvalho, L.R.F., Pool, C.S., Volatile organic compounds inside urban tunnels of São Paulo city, Brazil. Journal of the Brazilian Chemical Society, 16, 1210 (2005).

Yanowitz, J., McCormick, R.L., Effect of biodiesel blends on North American heavy-duty diesel engine emissions. European Journal of Lipid Science and Technology, 111, 763 (2009). 